\section{Leak of driving gas from Air-Shields ventilator}

To the Editor:

The design of the cylinder column which houses the bellows of the Air-Shields $@$ ventilator has evolved with each of the last three models. Initially, the cylinder (\#20-027-70) was secured to the ventilator housing by a wire cage (\#20-021-41); this was replaced by a cylinder (\#20-027-73) secured by a rigid retaining ring (\#20-078-00). In both cases, the cylinder base itself was sealed to the main ventilator body casting by a circular gasket. The most recent models (Ventimeter® Controller II and Ventimeter $B$ Ventilator II) include a cylinder which is glued to a square base (combined \#20-110-70); this, in turn, is attached to the ventilator circuit by a sealing gasket. We have found that the glued joint is subject to stress fractures, creating a potential for the leakage of driving gas.

Ventimeter $\otimes$ Controller II cylinders from two different ventilators in our institution were recently found to be leaking. Despite high inspiratory flow settings, preset tidal volumes were not achieved. On inspection, the cylinders were found to be separated from their support bases to varying degrees (Figure 1). Replacement cylinders supplied by the manufacturer were modified by the addition of two wedge supports (Figure 2). While this added

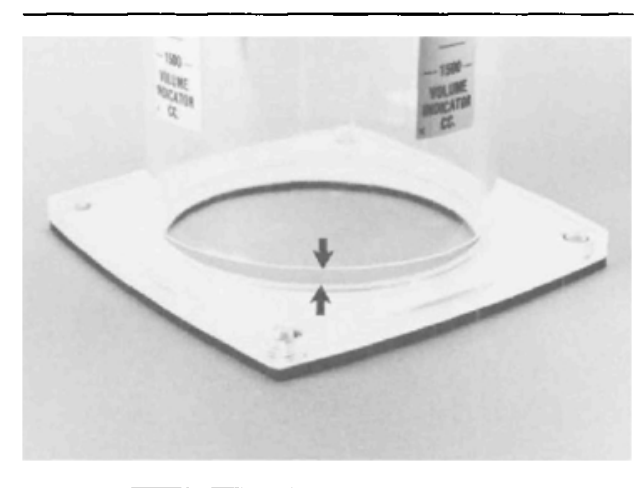

FIGURE 1 Ventilator cylinder column showing physical separation at the base as indicated by the arrows; traction on the cylinder and the base has been applied to demonstrate the separation.

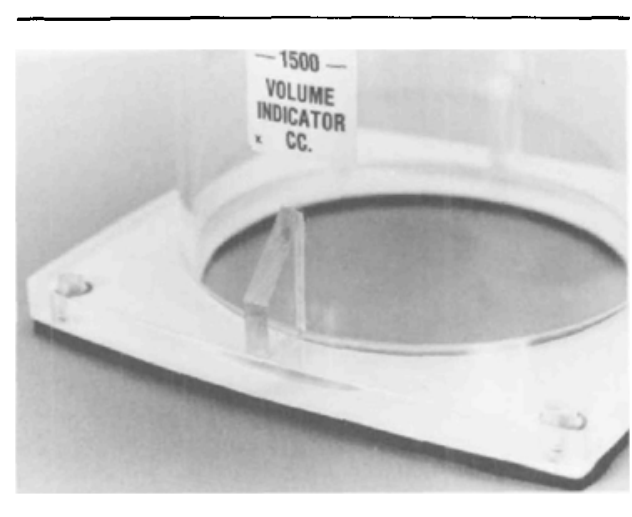

FIGURE 2 Replacement cylinder modified by the addition of two wedge supports.

mechanical strength to the design, there was no change in the apparent quality of the joint connection.

A small leak from this source may not be evident during a routine pre-anesthetic check, as increasing the inspiratory flow setting will compensate for the gas loss. The leak may, however, increase during mechanical ventilation. In this situation, conventional low airway pressure alarms and integral airway alarms (e.g. Drager Pressure Monitor DPM-S() may fail to actuate unless the leak is significant. The disconnect alarm on the Ventimeter@ Controller II itself is activated only when the bellows are empty. Clinically, the problem is best recognized by observing a reduction in pre-set tidal yolume and peak airway pressure. Alternatively, any suspect joint could be assessed by applying a soap solution and checking for bubbles produced by leaking gas.

Although ease of servicing and disposibility are attractive features of the Ventimeter(B) Controller II bellows unit, we consider the weakness described above as a negative aspect of the design, and a potential risk to patient safety.

Kwok Lee MD PH D FRCPC Sandra Jelenich MD FRCPC Elihu Henry RRT(C) Department of Anaesthesia The Wellesley Hospital Toronto, Ontario 